\title{
CHARGE syndrome: an update
}

\section{CHARGE syndrome is a rare, usually sporadic autosomal dominant disorder due in $2 / 3$ of cases to mutations within the CHD7 gene. The clinical definition has evolved with time. The 3C triad (Coloboma- Choanal atresia-abnormal semicircular (anals), arhinencephaly and rhombencephalic dysfunctions are now considered the most important and constant clues to the diagnosis. We will discuss here recent aspects of the phenotypic delineation of CHARGE syndrome and highlight the role of CHD7 in its pathogeny. We review available data on its molecular pathology as well as cytogenetic and molecular evidences for genetic heterogeneity within CHARGE syndrome.}

\section{In brief}

- CHARGE syndrome is an autosomal dominant disorder with a prevalence of one in 10 000. Most cases are sporadic, but, in rare instances, transmission from a mildly affected parent has been reported.

- The acronym CHARGE is based on the cardinal features identified when the syndrome was delineated: Coloboma, Heart malformation, choanal Atresia, Retardation of growth and / or development, Genital anomalies, and Ear anomalies. Since that time, new frequent clinical finding have been added to the clinical spectrum of CHARGE syndrome, such as dysmorphic features, rhombencephalic dysfunction, hypoplasia of the semicircular canals and arhinencephaly.

- Diagnostic criteria for CHARGE syndrome were updated by Blake and later Verloes, who stressed the importance of the 3C triad (Coloboma-Choanal atresia-abnormal semicircular Canals).
- CHARGE syndrome results from a dysblastogenetic and dysneurulative process and could be related by a common pathogenetic mechanism resulting in disturbed neural crest development.

- Using a CGH microaray approach, the gene CHD7 (in 8q12) was identified as causative for CHARGE syndrome in approximately $2 / 3$ of patients with a clinical diagnosis of CHARGE syndrome.

- CHD7 belongs to a large family of evolutionarily conserved proteins thought to play a role in chromatin organization. CHD7 is a regulatory element that potentially affects a large number of developmental pathways, explaining the pleiotropic nature of its phenotypic spectrum

- CHD7 (chromodomain helicase DNA-binding protein) mutations were in majority truncating mutations including nonsense mutations and frameshift mutations. Rarely, 8q12 microdeletion was present. No phenotype / genotype correlation could be proposed.
Damien Sanlaville ${ }^{1,2}$ and Alain Verloes ${ }^{3, *}$

'INSERM U781, Genetic Department, AP-HP Necker-Enfants Malades Hospital, Paris, France; ${ }^{2}$ Hospices Civils de Lyon, Cytogenetic Department, Edouard HERRIOT Hospital, Lyon, France; ${ }^{3}$ INSERM U676, Department of Medical Genetics, AP-HP Robert DEBRE University Hospital, Paris, France

European Journal of Human Genetics (2007) 15, 389-399. doi:10.1038/sj.ejhg.5201778; published online 14 February 2007

Keywords: CHARGE syndrome; CHD7; review

*Correspondence: Professor A Verloes, Département de Génétique, Hôpital Robert Debré, 48 Boulevard Sérurier, 75935, Paris Cedex 19, France. Tel: + 3314003 5342; Fax: + 3314003 5344;

E-mail: alain.verloes@rdb.aphp.fr

Received 24 January 2006; revised 25 October 2006; accepted 21 November 2006; published online 14 February 2007

\section{Introduction}

'CHARGE association' (or Hall-Hittner syndrome ${ }^{1}$ ) was originally delineated by Bryan Hall in 17 children with multiple congenital anomalies (MCA) with choanal atresia $^{2}$ and, independently, by HM Hittner in 10 MCA patients with coloboma. ${ }^{3}$ In a further review of 21 patients with choanal atresia and/or coloboma, R Pagon coined the term 'CHARGE', an acronym summarizing six cardinal clinical features: ocular Coloboma, Heart defects of any type, Atresia of the choanae, Retardation (of growth and/or of development), Genital anomalies and Ear anomalies (abnormal pinnae or hearing loss). ${ }^{4}$ Patients with CHARGE syndrome were reported before its formal delineation (ie Edward's case, ${ }^{5}$ or patient 3 in Angelman's report ${ }^{6}$ ) As CHARGE is a multiple anomaly pattern proven to be pathogenetically related, 'CHARGE syndrome' should be used instead of 'CHARGE association'. 7 
CHARGE syndrome

D Sanlaville and A Verloes

390

In a national study of CHARGE syndrome conducted through the Canadian Pediatric Surveillance Programme, its incidence was evaluated at $1 / 8500$, in accordance with a previous reports of $1 / 12500$ in North America. ${ }^{8,9}$ By contrast, extrapolation from the incidence of choanal atresia lead to far lesser apparent incidence in Europe: $1 / 110000$ births. ${ }^{10}$ Almost all cases are sporadic, and mean paternal age is increased (34 years ${ }^{11}$.) Recurrence rate is close to $1 \%$. Recurrences in a sibship ${ }^{4,12}$, parent-to-child transmission ${ }^{3,4,13,14}$ and concordant MZ twins have been reported. ${ }^{15-18}$

\section{Clinical manifestations}

More than 400 patients have been reported in the world literature, including several large series and reviews $^{4,9,11,19-21}$ of which frequencies of the major signs are extrapolated. In the present review, we will stress the more recently delineated anomalies. Figure 1 presents recommended diagnostic algorithm.

\section{Dysmorphia}

The face is typically square-shaped, with narrow bifrontal diameter, broad nasal bridge, small mouth and inverted V-shaped upper lip. Facial palsy and dysplasia of the pinnae often lead to significant facial asymmetry. Cleft lip and palate are present in 15-20\%. Several dental anomalies are reported such as oligodontia and delayed eruption of teeth. $^{22}$

\section{Ocular anomalies}

Chorioretineal coloboma, with $(40 \%)$ or without microphthalmia, is present in $75-90 \%$. Coloboma is often of small size, and must be actively searched by fundoscopy. In a minority of case, they may extend to the iris and/or the optic disk. Bilateral involvement is present in $70-80 \%$. Among patients with uveal coloboma, CHARGE could represent almost $20 \% .^{23}$ Other anomalies include hypoplasia of optic nerve, anophthalmia, nystagmus, squint and refractive errors. Palpebral defects have been reported such as ankyloblepharon, coloboma of the lid and atresia of the lachrymal ducts. ${ }^{11,18,20,24}$ Most patients with CHARGE syndrome have preserved vision.

\section{Auditory and vestibular anomalies}

The three segments of the ear are affected. In 95-100\%, the pinnae are asymmetrically misshaped, low set, anteverted, cup-shaped, wide, but with reduced vertical height (Figure 2). Preauricular tags, hypoplastic auditory canal and microtia can be associated. Middle ear is sometimes affected: ${ }^{25,26}$ absence of the stapedius muscle, absence of the oval window, and hypoplastic incus and stapes, with ossicular chain fixation. ${ }^{25,27}$ Chronic serous otitis is often present, and may contribute to hypoacousia.

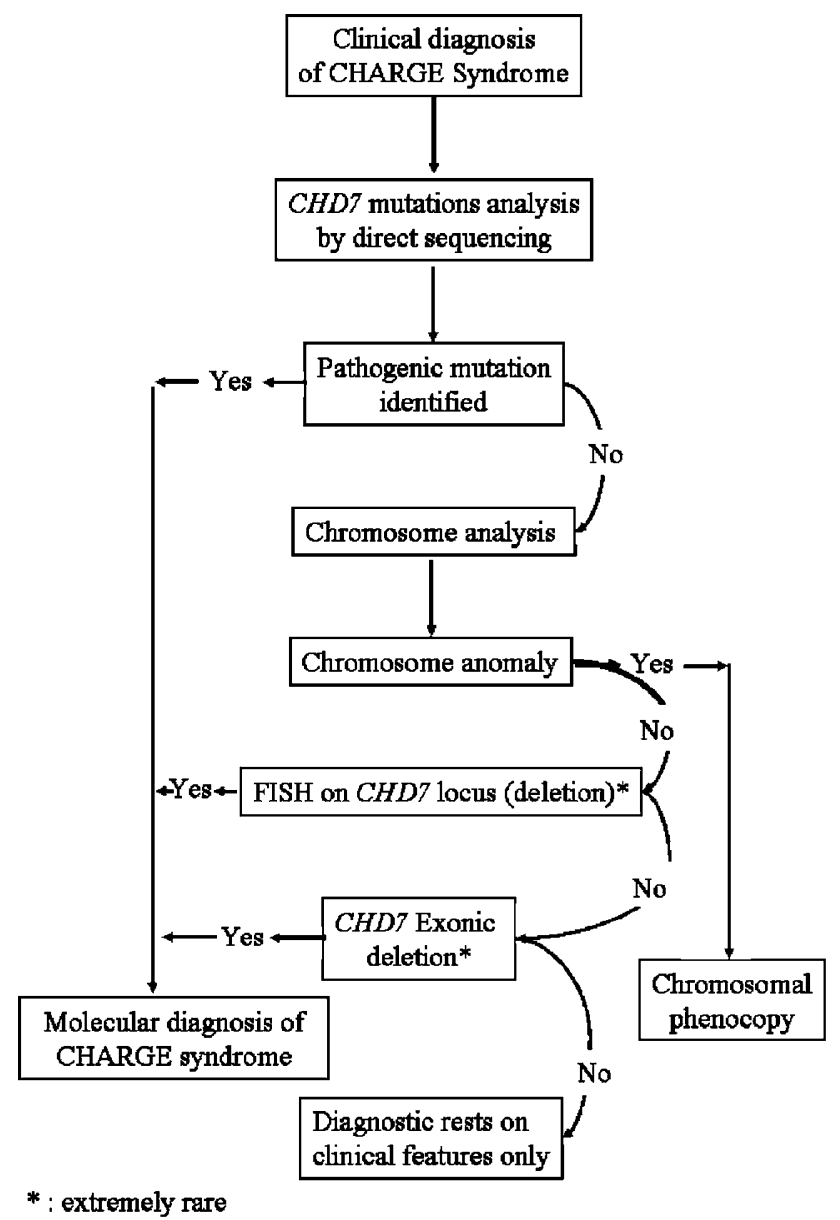

Figure 1 Diagnostic algorithm for CHARGE syndrome. This algorithm would lead to definite molecular confirmation in $60 \%$ of clinically validated CHARGE patients.

Initially described in $1976,{ }^{28}$ but definitively settled by Guyot $^{29}$ who described the 'CHARGE type of Mondini dysplasia', malformation of the inner ear has become increasingly important in the diagnostic workup, with the development of inner ear imaging. The prevalence of inner ear anomalies could be higher than $90 \% .^{26,30}$ These consist of a specific form of labyrinthine dysplasia that includes complete absence of the pars superior (utricle and semicircular canals) with or without Mondini dysplasia of the pars inferior (cochlea and saccule). Although Mondini dysplasia is relatively nonspecific, and can be observed in many syndromal deafness, aplasia of the semicircular canals and hypoplastic uncus are probably the most specific anomaly of CHARGE syndrome. ${ }^{31,32}$ In a recent series, nine out of 15 patients ascertained by this anomaly had CHARGE. ${ }^{33}$ In the newborn, agenesis of the semicircular canals can be visualized on plain profile X-ray of the skull (Figure 3a, b). In older patients, computerized tomography (Figure 3c, d) or MRI is necessary. 
Malformation of the inner ear results in complete absence of nystagmic response to bithermal caloric stimuli. Vestibulo-ocular responses to earth-vertical axis rotation are abolished, but otolith vestibulo-ocular responses to the offvertical axis rotation test are preserved. ${ }^{34}$

Deafness affects $60-90 \%$ of cases. The commonest hearing defects are severe conductive or mixed loss, and usually affects more the high frequencies than the low ones. ${ }^{35}$

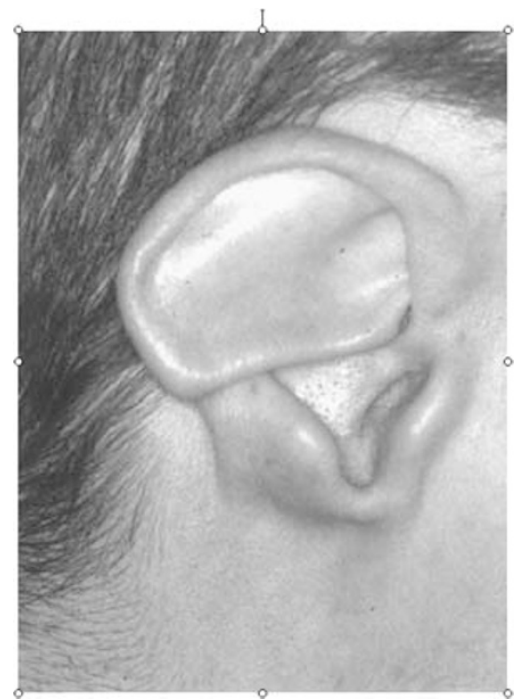

Figure 2 Typical cup-shaped aspect of 'CHARGE ear'.

\section{Choanal atresia and other ENT anomalies}

This sign is present in $35^{21}$ to $65 \%$ of cases. Atresia is most often osseous and bilateral. In a series of patients with choanal atresia, CHARGE syndrome was found in 38/130 cases. ${ }^{36}$ Laryngeal cleft, subglottic stenosis, tracheomalacia, vocal cord palsy have been reported. ${ }^{26}$ Gastroesophageal reflux affects at least half of the cases. Velar incompetence seems common. ${ }^{15,18}$ Choanal atresia is usually absent when palate is cleft.

\section{Central nervous system malformations}

Depending on ascertainment and mode of investigation, $55-85 \%$ of patients have definite CNS anomalies. ${ }^{37,38}$ Arhinencephaly or hypoplastic olfactory bulbs, with or without other defects, is the most common defect. ${ }^{39}$ It was observed by MRI scan in $18 / 18$ patients. ${ }^{38}$ Anosmia has recently be found to be a common anomaly, $^{40}$ in relation with abnormal olfactory bulbs. Holoprosencephaly sequence is the next most common anomaly. Many other defects have been reported, in the forebrain (eg dysgenesis of the frontal lobe, agenesis of the septum pellucidum, nodular heterotopias, lissencephaly) and the hindbrain (Dandy-Walker anomaly, vermis hypoplasia, stenosis of Sylvius aqueduct). CNS malformations are strongly associated with choanal atresia.
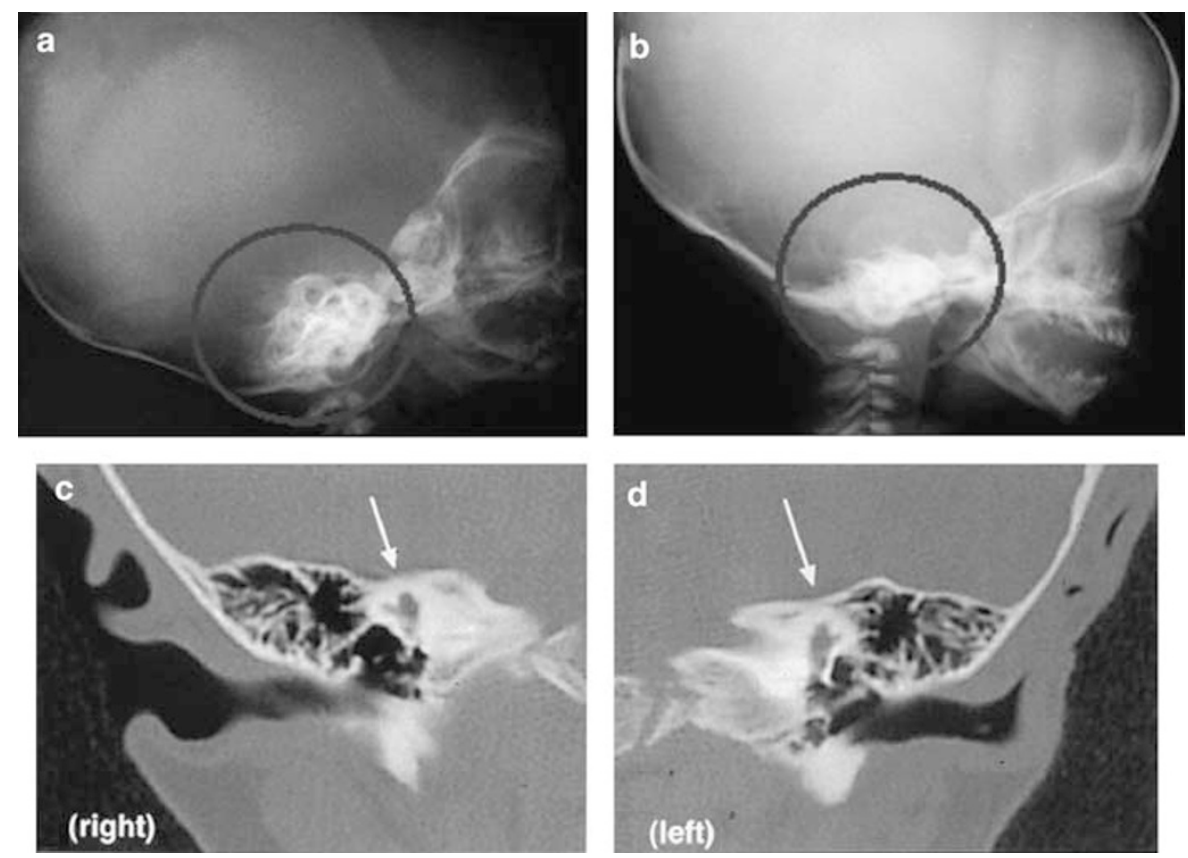

Figure 3 (a) Profile view of normal newborn skull. The semicircular canals are densely mineralized, bulging over the petrous bone (circle). (b) Profile of the skull in an affected newborn. Note absence of the canals. (c-d) Computerized tomography scan of the inner ear of an affected child, revealing absence of the canals. 


\section{Rhombencephalic dysfunction (excluding sensorineural deafness)}

Besides the acoustic nerve VIII, all other cranial nerves can be affected in CHARGE syndrome, usually in association. ${ }^{41}$ Of children with the CHARGE syndrome, 50-90\% have congenital facial paralysis and $80 \%$ have feeding and swallowing difficulties. ${ }^{42}$ In Byerly's review of 150 cases, the affected nerves were nerve VII (43\%), IX and/or X (31\%), III and VI (2\% each). Facial palsy is usually asymmetric or unilateral. Multiple involvements may result in Moebius sequence. Tellier et al. ${ }^{11}$ stressed the complex dysregulation of brainstem functions in neonate and infants with CHARGE syndrome. Pharyngeal incoordination is associated with a high risk of aspiration $\left(30 \%{ }^{42}\right)$. Many children require G-tube feeding or gastrostomy for several months or years. Thermal dysregulation and irregularities of cardiac rhythm are other signs of rhombencephalic dysfunction.

\section{Hypothalamo-hypophyseal dysfunction and Kallmann syndrome}

Hypothalamo-hypophyseal dysfunction is the cause of growth retardation, genital hypoplasia and delayed puberty. Seven out of nine boys tested before the age of 5 months during the neonatal peak period had extremely low testosterone levels; LH response to GnRH stimulation was variable during the first year of life and not correlated with existing clinical abnormalities. ${ }^{38}$ By contrast, no endocrine dysfunction were demonstrable in four children with short stature and micropenis, ${ }^{43}$ indicating that the hypothalamo-hypopituitary control of gonadotrophin may be variably affected during life. Delayed or absent puberty affected $2 / 3$ of 21 cases, in relation with hypogonadotropic hypogodadism. ${ }^{44}$ In Jongmans series (with CHD7 mutation), gonadotrophin deficiency was present in $7 / 10$ girls and $6 / 7$ boys age over $14-15$ years. ${ }^{45}$ Hormone substitution is recommended.

\section{Growth retardation}

Despite its presence in the original acronym, growth retardation is seldom a primary problem in CHARGE syndrome. Most patients have low normal birth weight and length (around 10th centile). ${ }^{46}$ Postnatal growth retardation should be in relation to feeding difficulties and/or surgical problems. ${ }^{47}$ Growth tends to catch up after infancy, but insufficient and inadapted intakes may have adverse outcome on growth and bone mineralization. Osteoporosis seems frequent in elder patients with CHARGE, because of 'relative' malnutrition and insufficient secretion of steroids. True GH deficiency is exceptional.

\section{Genito-urinary anomalies}

Genital anomalies are observed in $50-70 \%$ of cases (males: 80-90\%, females: $15-25 \%$ ). Thus, the use of this sign in diagnostic score biases diagnosis to boys. Hypoplastic external genitalia is the most common anomaly: $80 \%$ of boys have micropenis and/or cryptorchidism, and $1 / 3$ of the girls have hypoplastic labiae majorae. Mullerian tract agenesis has been reported twice. ${ }^{48}$ Sex steroid therapy has been tried for penile growth and descent of testis in males with CHARGE syndrome. The main use for testosterone is for delayed male puberty in adolescence. Females often require hormone replacement at puberty. ${ }^{49}$ Anomalies of the urinary tract may be present in $10-40 \%$, such as renal ectopia, horseshoe kidneys, ureteral anomalies, but are nonspecific and may be asymptomatic, or diagnosed beyond infancy because of infections.

\section{Other visceral malformations}

Congenital heart defects (CHD) are observed in 50-85\% of cases. Conotruncal defects as Fallot tetralogy (1/3 of cases), atrioventricular canal, VSD, ASD, aortic coarctation an PDA represent $75 \%$ of the defects. Aberrant subclavian arteries are often present. CHD are statistically associated with tracheo-esophageal fistula, renal anomalies and cleft lip/palate. ${ }^{50}$

\section{Immune deficiency}

Immune deficiencies is uncommon and variable in CHARGE: (impaired T-cell proliferation, T-cell lymphopenia, immunoglobulin G2 subclass deficiency ${ }^{20,51,52}$ ). Rarely patients may exhibit true DiGeorge syndrome. ${ }^{53}$

\section{Orthopedic problems}

Limb anomalies, usually minor, are reported in $37 \%{ }^{54}$ Spine may be malformed: vertebral fusions, hemivertebrae, abnormal cervico-cranial junction, abnormal number of ribs. Scoliosis is a frequent problem in older children with CHARGE (60\% of patients beyond infancy ${ }^{55}$ ). It is promoted by hypotonia, but may be worsened in case of vertebral defects.

\section{Mental retardation and behavioral disturbances}

Motor milestones are commonly delayed, at least partially because of vestibular and visual impairments. Sitting is possible after 1 year and walking occurs between 24 and 36 months. Mental retardation (MR), that is, IQ $<70$, is present in more than $70 \%$ of cases. IQ range from normal (115 in Money and Norman ${ }^{56}$ ) to severe retardation. In Jongmans series of patients with CHD7 mutations, 8/32 patients had IQ above 70. There is strong mixture of primary developmental factors and acquired postnatal damages in the etiology of MR. In a recent series, ${ }^{11}$ almost $50 \%$ of patients had MRI evidences of anoxo-ischemic brain lesions. In series of 21 children, ${ }^{57}$ extensive bilateral coloboma with poor vision, microcephaly and brain malformation are the only three parameters that were predictive of poor intellectual outcome; the main psychomotor milestones (normally reached before age 4 years) 
Table 1 Frequencies of major anomalies in patients with CHD7 from two series compared with the CHD7-negative patients from some of them. No significant differences can be shown

\begin{tabular}{llcccr}
\hline Sign & Jongmans & Lalani CHD7 mutated & Combined & Lalani CHD7 (not mutated) & $\mathrm{P}\left(\chi^{2}\right)$ \\
\hline CHD & $31 / 47$ & $54 / 59$ & $85 / 106(80 \%)$ & $30 / 42$ & 0.68 \\
Coloboma & $33 / 47$ & $55 / 62$ & $88 / 109(81 \%)$ & $30 / 43$ & 0.60 \\
Facial asymmetry & $10 / 47$ & $36 / 56$ & $46 / 103(45 \%)$ & $13 / 39$ & 0.42 \\
Choanal atresia & $17 / 47$ & $34 / 57$ & $51 / 104(49 \%)$ & $23 / 39$ & 0.56 \\
Hearing loss & $37 / 41$ & $54 / 59$ & $91 / 100(91 \%)$ & $36 / 38$ & 0.88 \\
Inner ear anomaly & $21 / 21$ & $21 / 22$ & $43(42 ?) ? / 44(98 \%)$ & $9 / 10$ & 0.87 \\
External ear anomaly & $47 / 47$ & $59 / 62$ & $106 / 109(97 \%)$ & $39 / 42$ & 0.86 \\
Urogenital anomalies & $17 / 22$ (males) & $29 / 53$ & $46 / 75(61 \%)$ & $26 / 39$ & 0.79 \\
Cleft lip/palate & $17 / 47$ & $18 / 60$ & $35 / 107(33 \%)$ & $9 / 41$ & 0.37 \\
TE fistula & $8 / 47$ & $10 / 55$ & $18 / 102(18 \%)$ & $3 / 40$ & \\
\hline
\end{tabular}

were severely delayed, although intellectual outcome (at primary-school age) was satisfactory for half the children. There has been a recent interest on behavioral aspects of CHARGE syndrome. ${ }^{58,59}$ Children with CHARGE syndrome frequently have relatively low adaptive behavior skills, motor impairments being particularly significant. Adaptative skills are negatively correlated with age at walking, degree of hearing and visual impairment and medical involvement, and tend to decrease with aging. Nevertheless, individual adaptive behavior scores revealed a broader and higher reaching range of ability. ${ }^{60}$ Patients with CHARGE syndrome often are diagnosed with obsessive-compulsive disorder, attention deficit disorder, Tourette syndrome and autism. The diagnosis of autism remains challenging in individuals with sensory impairments, although autistic features appear more common in CHARGE than in other syndromes sharing a similar level of mental handicap. Whether that symptomatology is really autism or only the consequence of sensory deprivation remains disputed.

\section{Clinical particularities of CHARGE syndrome owing to CHD7 mutation}

The frequency of signs in the subgroup of patients carrying a CHD7 mutation has recently been reported in 69/107 patients ${ }^{45}$ and 59/110 patients ${ }^{61}$ (Table 1) In a recent small series, Aramaki et al. ${ }^{62}$ found CHD7 mutations in 17/24 (74\%). Comparison between patients with or without mutation of $C H D 7$ is only available in Lalani's series. They showed a relative excess of coloboma, PDA and facial palsy, whereas the two groups were not different for the other types of CHD, choanal atresia, deafness, external and internal ear anomaly, urogenital and tracheoesophageal anomalies and cleft. ${ }^{61}$ These differences disappear when the two large series are combined (see Table 1). Postnatal growth also appeared more severely impaired in the mutated group (mean stature:-2.53 vs $-1.76 \mathrm{SD}$ ). Vestibulo-cochlear defects appears to be the most important feature of CHD7-related CHARGE syndrome; altogether, $57 / 58$ mutation-positive patients for which appropriate studies were performed, had anomalies of the semicircular canal.

It must be stressed that the three series are made of clinically typical cases and are thus self-limiting. As for other developmental genes, the spectrum of clinical manifestations linked to CHD7 mutations is expected to become wider and more variable than the strict clinical phenotype that can be driven from these early series.

\section{Diagnostic criteria}

Originally, to make a diagnosis of CHARGE complex, four to six cardinal signs were needed to be present, one being either choanal atresia or a coloboma. ${ }^{4,63}$ These criteria were updated by Blake et $a l^{8}$, who proposed new diagnostic criteria, expanding the original picture to encompass brainstem anomalies and visceral malformations. Verloes proposed renewed clinical criteria, focusing on the coloboma-choanal atresia-abnormal semicircular canals (3C) triad, and giving a formal definition for partial and atypical CHARGE syndromes. ${ }^{32}$ Table 2 presents the three diagnostic systems with their inclusion criteria. At this point of knowledge, they remain important in preselecting patients for CHD7 mutational screen (although this may change when the full clinical spectrum of CHD7 mutants will be known). A combination of coloboma, choanal atresia and abnormal semicircular canals (3C) is highly predictive of the presence of a CHD7 mutation. ${ }^{61}$ On the other hand, only $1 / 47$ screen-positive patients did not fulfill these criteria. Nevertheless, the clinical spectrum of CHD7 mutations is not yet fully defined and further series are still necessary to refine the diagnostic criteria to search a CHD7 mutation.

\section{Prenatal diagnosis and fetal pathology}

Prenatal diagnosis of CHARGE syndrome has been reported at least twice. ${ }^{64,65}$ Many developmental anomalies of CHARGE syndrome can be detected by fetal ultrasonography. Hydramnios is present in 50\% of cases with choanal atresia ${ }^{20}$ and with tracheo-esophageal fistula. Absence of semicircular canal is detectable by ultrasound, 
Table 2 Clinical criteria

\begin{tabular}{lll}
\hline & Major criteria & Minor criteria \\
\hline Pagon & 1. Choanal atresia & $\begin{array}{l}\text { 1. Heart defects of any type } \\
\text { 2. Ocular colobomale }\end{array}$ \\
& $\begin{array}{l}\text { 2. Retardation (of growth and/or of } \\
\text { development), } \\
\end{array}$ & $\begin{array}{l}\text { 3. Genital anomalies } \\
\text { 4. Ear anomalies (abnormal pinnae or hearing } \\
\text { loss) }\end{array}$
\end{tabular}

Blake 1. Coloboma - of iris, retina, choroid, disc; microphthalmia

2. Choanal atresia - unilateral/bilateral, membranous/bony, stenosis/atresia

3. Characteristic ear abnormalities - external ear (lop or cup-shaped), middle ear (ossicular malformations, chronic serous otitis), mixed deafness, cochlear defects

4. Cranial nerve dysfunction - facial palsy (unilateral or bilateral), sensorineural deafness and/or swallowing problems
Verloes 1. Ocular coloboma

2. Choanal atresia

3. Hypoplasia of semicircular canals
1. Genital hypoplasia - males: micropenis, males and females: delayed, incomplete pubertal development

2. Developmental delay - delayed motor milestones, language delay, mental retardation 3. Cardiovascular malformations - all types, especially conotruncal defects (eg, tetralogy of Fallot), AV canal defects, and aortic arch anomalies

4. Growth deficiencies - short stature, growth hormone deficiency

5. Orofacial cleft - cleft lip and/or palate

6. Tracheoesophageal-fistula -

tracheoesophageal defects of all types

7. Characteristic face - sloping forehead, flattened tip of nose

1. Rhombecephalic dysfunction (brainstem and cranial nerve III to XII anomalies, including sensorineural deafness)

2. Hypothalamo-hypophyseal dysfunction (including $\mathrm{GH}$ and gonadotrophin defects)

3. Malformation of the ear (internal or external)

4. Malformation of mediastinal organs (heart, esophagus,)

5. Mental retardation
Four majors OR three ajors +three minors

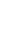

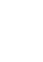




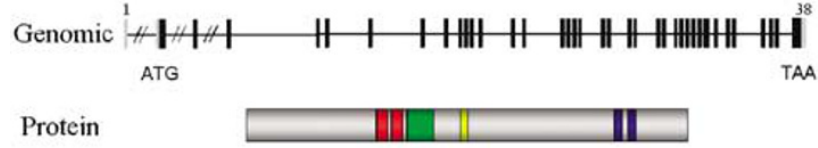

$\begin{array}{ll}\text { IChromodomain } & \text { \Helicase } \\ \text { ISNF2 } & \text { |BRK }\end{array}$

Figure 4 Genomic (up) and protein (bottom) map of CHD7.

template. ${ }^{72}$ CHD7 protein counts several functional domains: two chromo (chromatin organization modifier), one SNF2/SWI, one helicase and two BRK domains (Figure 4). Chromo domains are implicated in the recognition of lysine-methylated histone tails and of DNA (and RNA) targets. They mediate chromatin interactions in a variety of different protein context. ${ }^{73}$ SWI/SNF2 domains are found in proteins characterized by DNA-dependent ATPase activity, involved with the maintenance, transmission and expression of the eukaryotic genome by regulating the structure of chromatin. ${ }^{74}$ The helicase domain plays a role in DNA strand separation during replication, repair, recombination and transcription. Function of the BRK domain is unknown.

By semi-quantitative reverse transcriptase-polymerase chain reaction assay, CHD7 is expressed ubiquitously in fetal and adult tissues: including eye, olfactory epithelium, inner ear and vascular system. ${ }^{68}$ By contrast, in 10.5-day mice embryos, Chd7 is selectively expressed in the outflow tract of the heart, optic vesicle, facio-acoustic preganglion complex, forebrain, hindbrain, olfactory pit and mandibular component of the first branchial arch. ${ }^{61}$ Microarray gene-expression analysis of lymphoblastoid cell lines showed a signature pattern of gene-expression differences that distinguished the individuals with CHARGE syndrome with $C H D 7$ mutation from the controls.

The function of CHD7 protein is still largely unknown. The closely related CHD1, CHD3 and CHD4 are known to contribute to the nucleosome remodeling and deacetylating complex, leading to anticipate a similar function for CHD7. CHD7 has recently been shown to be a nuclear protein, physically associated with chromatin. It colocalizes with promoters specifically marked with methylation of lysine 4 on histone $\mathrm{H} 3$ (H3K4me), suggesting that CHD7 targets a specific subset of transcriptionally active genes, including several genes within the HOXA cluster, and may act as an activator of transcription. ${ }^{75}$

Published mutations in $\mathrm{CHD7}$ are scattered throughout the gene, and do not show preferential domain aggregation, nor hot spot (although some identical mutations were found in two or three unrelated individuals.) They include missense, nonsense and splicing mutations Furthermore, small intragenic deletions have been show in one case $^{76}$ (Table 3). In Lalani's series $61,73 \%$ of mutations were predicted to be truncating, clearly indicating haploinsufficiency as the pathogenic mechanism. There is no clear genotype/phenotype relationship. Mutations were shown to be dominantly transmitted in some families, and proven recurrence of a mutation in two sibs confirmed the possibility of germinal mosaicism. Interestingly, a pair of affected MZ twins ${ }^{61}$ showed remarkable discrepancies in the cardiac malformation patterns. Somatic mosaicism was detected in the unaffected mother of a sib pair, supporting the existence of germline mosaicism. $^{45}$

With the ENU mutagenesis program, Bosman et $a l^{77}$ reported the identification of mutations in the Chd7 gene in nine of these mice mutant, including six nonsense and three splice-site mutations. These Wheels heterozygous mutant mice revealed a range of defects with reduced penetrance, such as truncations of the lateral semicircular canal, cleft palate, choanal atresia, septal defects of the heart, hemorrhages, prenatal death, vulva and clitoral defects and keratoconjunctivitis sicca that mimics human CHARGE syndrome. Lalani $e a^{61}$ studied mouse embryo whole-mount and section in situ hybridization and showed the expression of $C h d 7$ in the outflow tract of the heart, optic vesicle, facio-acoustic preganglion complex, brain, olfactory pit and mandibular component of the first branchial arch. The in situ hybridization analysis of the CHD7 gene during early human development by Sanlaville $^{78}$ showed a good correlation between specific CHD7 expression pattern and the developmental anomalies observed in CHARGE syndrome. In particular, CHD7 is expressed in the semicircular canals, the forebrain, pituitary gland, olfactory bulbs and nerves, the nasal epithelia, the neural retina, the optic nerve sheath and the anterior and median lobes of the pituitary gland.

SEMA3E After having mapped a de novo balanced $\mathrm{t}(2 ; 7)(\mathrm{p} 14 ; \mathrm{q} 21.11)$ translocation, in a CHARGE patient, interrupting the SEMA3E gene located in $7 \mathrm{q} 21$, Lalani ${ }^{79}$ reported a de novo missense mutation S703L of SEMA3E in another affected patient with iris coloboma, choanal atresia, ear malformation, profound deafness, tetralogy of Fallot, developmental delay and growth retardation. Arraybased expression analysis showed a non-CHD7 pattern in this patient. Although this amino acid is conserved in human, mouse and rat, the role of SEMA3E remains putative and functional relations between $\mathrm{CHD} 7$ and SEMA3E unexplained.

\section{Chromosomal anomalies}

Several chromosomal anomalies (including trisomy 13 and 18) show elements of CHARGE syndrome. More specifically, 11qter deletion and 13qter deletion are confusing, as coloboma, heart defects and holoprosencephaly/arhinencephaly are commonly reported. Table 4 summarizes the chromosomal anomalies reported with convincing 
Table 3 Types and frequency of CHD7 mutations reported in CHARGE patients

\begin{tabular}{|c|c|c|c|c|c|c|c|c|c|c|}
\hline \multirow[b]{2}{*}{ Nonsense } & \multicolumn{2}{|c|}{ Jongmans } & \multicolumn{2}{|c|}{ Lalani } & \multicolumn{2}{|c|}{ Aramki } & \multicolumn{2}{|c|}{ French series $^{\mathrm{a}}$} & \multicolumn{2}{|c|}{ Total } \\
\hline & 31 & $45 \%$ & 28 & $44 \%$ & 6 & $35 \%$ & 27 & $36 \%$ & 92 & $44 \%$ \\
\hline Frame shift & 17 & $25 \%$ & 19 & $30 \%$ & 7 & $41 \%$ & 32 & $43 \%$ & 75 & $36 \%$ \\
\hline Splice site & 13 & $19 \%$ & 10 & $16 \%$ & 3 & $18 \%$ & 7 & $9 \%$ & 33 & $16 \%$ \\
\hline Missense & 8 & $12 \%$ & 7 & $11 \%$ & 0 & $0 \%$ & 8 & $11 \%$ & 23 & $11 \%$ \\
\hline intragenic deletion & 0 & & 0 & & 1 & $6 \%$ & 0 & & 1 & $0.5 \%$ \\
\hline & 69 & & 64 & & 17 & & 74 & & 207 & \\
\hline
\end{tabular}

Personal communication (Sanlaville et al, Assises de Génétique, 2006, Montpellier, France).

Table 4 Cytogenetic anomalies, not involving the $8 q 12$ region, reported with CHARGE syndrome

\begin{tabular}{|c|c|c|c|c|c|c|c|c|}
\hline Ref & Karyotype & C & $H$ & $A$ & $R$ & G & $E$ & Criteria \\
\hline 92 & $45, \mathrm{XX},-3,-22,+\operatorname{der}(3) \mathrm{t}(3 ; 22)(\mathrm{p} 25 ; \mathrm{q} 11.1)$ & - & + & + & + & girl & - & $3 / 6$ \\
\hline & $46, X Y,-18,+\operatorname{der}(18) t(2 ; 18)(q 37.3 ; q 22.3)$ & - & + & + & + & + & $?$ & $4 / 6$ \\
\hline 93 & 46,XY,-3,+del 3(pterp21.2::p12qter) & + & + & + & + & + & + & $6 / 6$ \\
\hline 94 & $46, X X$,invdup $(14)(q 22-q 24.3)$ & + & + & + & + & + & + & $6 / 6$ \\
\hline 95 & $47, x X,+18$ & + & + & + & $?$ & $?$ & + & $4 / 6$ \\
\hline 96 & $46, X X$, der(21)t(19;21)(q13.1;q22.3)mat & + & + & $?$ & + & $?$ & + & $4 / 6$ \\
\hline 80 & $46, X X$, del 22q11.2 & + & + & + & + & $?$ & + & $5 / 6$ \\
\hline 97 & $46, X, \operatorname{der}(X) t(X ; 2)(p 22.1 ; q 33)$ & - & + & + & + & + & + & $5 / 6$ \\
\hline 98 & $46, X Y, \operatorname{dup}(1)(q 31-q 43)$ & - & + & - & + & + & + & $4 / 6$ \\
\hline 99 & $46, X X, t(5 ; 14)(p 15 ; q 13)$ & + & - & - & + & + & + & $4 / 6$ \\
\hline 100 & Trisomie 8q22qter & - & + & + & $?$ & + & - & $4 / 5$ \\
\hline
\end{tabular}

CHARGE phenotype. Although the overlap of CHARGE and DiGeorge syndromes has been repeatedly reported, reports of the deletion in bona fide CHARGE remains exceptional ${ }^{80} \mathrm{~A}$ single patient has been reported with both $\operatorname{del}(22)(\mathrm{q} 11)$ and CHD7 mutation. ${ }^{45}$

Phenocopies CHARGE syndrome has been reported in patients exposed in utero to thalidomide, retinoic acid, hydantoines, alcohol or maternal diabetes. ${ }^{81-85}$ Those reports are anecdotic and could be fortuitous.

\section{Pathogeny}

Abnormal events, in CHARGE occurs at the end of the first month of development (closure of colobomic cleft: days 34-44; rupture of bucopharyngral membrane: day 35-38, colonization of cardiac tube by neural crest cells: day $32-$ 45; cochlea: begins at day 36) to after the 9th week of gestation. CHARGE syndrome results from a dysblastogenetic and dysneurulative process: abnormal differentiation of cephalic mesoderm and ectoderm (otic placode and first branchial cleft), abnormal setting (differentiation, migration, survival) of neural crest cells, abnormal interaction of neural crests (forming e.a. first and second arch) with the cephalic mesoderm and the developing forebrain, and concomitant disorder in the development of the prosencephalon, mesencephalon and rhombencephalon out of which the neural crest cells have migrated. CHARGE is thus a complex neurocristopathy. ${ }^{37,86-88}$

Van Meter, ${ }^{88}$ and later Kallen, ${ }^{89}$ suggested that oculoauriculo-vertebral, VATER and CHARGE could be related by a common pathogenetic mechanism resulting in disturbed neural crest development. In particular, agenesis of semicircular canals was reported in Goldenhar syndrome. ${ }^{90}$ From a nosographic point of view, CHARGE syndrome can also be regarded as a syndromal form of Kallmann syndrome, which is defined by hypogonadotropic hypogonadism combined with a defective sense of smell and abnormal olfactory bulb development. Hill ${ }^{91}$ reported Kallmann syndrome with agenesis of the semicircular canals.

\section{Conclusions}

CHARGE syndrome is a clinical diagnosis. The clinical scores have shown their robustness, as almost all patients with CHD7 mutation fit them (Figure 1). Pathogeny of the CHARGE remains puzzling: CHD7 is a regulatory element that potentially affects a large number of developmental pathways, explaining the pleiotropic nature of its phenotypic spectrum. The next step will be to understand precisely which genes and pathways are under the control of CHD7, whether SEMA3E is or not another CHARGE gene 
and which molecular partner(s) can explain the $40 \%$ of non-mutated CHARGE syndrome.

\section{References}

1 Graham Jr JM: A recognizable syndrome within CHARGE association: Hall-Hittner syndrome. Am J Med Genet 2001; 99: 120-123.

2 Hall BD: Choanal atresia and associated multiple anomalies. J Pediat 1979; 95: 395-398.

3 Hittner HM, Hirsch NJ, Kreh GM, Rudolph AJ: Colobomatous microphthalmia, heart disease, hearing loss, and mental retardation-a syndrome. J Pediat Ophth Strab 1979; 16: 122-128.

4 Pagon RA, Graham Jr JM, Zonana JYSL: Coloboma, congenital heart disease, and choanal atresia with multiple anomalies: CHARGE a\&ssociation. J Pediat 1981; 99: 223-227.

5 Edwards JA, Young RB, Finlay HLV: Coloboma with multiple congenital anomalies. BMJ 1961; 26: 586-587.

6 Angelman H: Syndrome of coloboma with multiple congenital abnormalities in infancy. BMJ 1961; 29: 1212-1214.

7 Lubinsky MS: Properties of associations: identity, nature, and clinical criteria, with a commentary on why CHARGE and Goldenhar are not associations. Am J Med Genet 1994; 49: 21-25.

8 Blake KD, Davenport SL, Hall BD et al: CHARGE association: an update and review for the primary pediatrician. Clin Pediat 1998; 37: $159-173$.

9 Issekutz KA, Graham Jr JM, Prasad C, Smith IM, Blake KD: An epidemiological analysis of CHARGE syndrome: preliminary results from a Canadian study. Am J Med Genet A 2005; 133: 309-317.

10 Harris J, Robert E, Kallen B: Epidemiology of choanal atresia with special reference to the CHARGE association. Pediatrics 1997; 99: 363-367.

11 Tellier AL, Cormier-Daire V, Abadie V et al: CHARGE syndrome: report of 47 cases and review. Am J Med Genet 1998; 76: 402409 .

12 Finel E, Parent P, Giroux JD, de PL: The CHARGE association. Arch Pediat 1996; 3: 1020-1025.

13 Metlay LA, Smythe PS, Miller ME: Familial CHARGE syndrome: clinical report with autopsy findings. Am J Med Genet 1987; 26: 577-581.

14 Mitchell JA, Giangiacomo J, Hefner MA, Thelin JW, Pickens JM: Dominant CHARGE association. Ophthalmic Paed Genet 1985; 6: $271-276$.

15 Oley CA, Baraitser M, Grant DB: A reappraisal of the CHARGE association. J Med Genet 1988; 25: 147-157.

16 Levin DL, Muster AJ, Newfeld EA, Paul MH: Concordant aortic arch anomalies in monozygotic twins. J Pediat 1973; 83: $459-461$.

17 Farquhar J, Carachi R, Raine PA: Twins with oesophageal atresia and the CHARGE association. Eur J Pediatr Surg 2002; 12: 56-58.

18 Chestler RJ, France TD: Ocular findings in CHARGE syndrome. Six case reports and a review. Ophthalmology 1988; 95: $1613-1619$.

19 Davenport SL, Hefner MA, Mitchell JA: The spectrum of clinical features in CHARGE syndrome. Clin Genet 1986; 29: 298-310.

20 Blake KD, Russell-Eggitt IM, Morgan DW, Ratcliffe JM, Wyse RK: Who's in CHARGE? Multidisciplinary management of patients with CHARGE association. Arch Dis Childhood 1990; 65: $217-223$.

21 Stromland K, Sjogreen L, Johansson M et al: CHARGE association in Sweden: malformations and functional deficits. Am J Med Genet A 2005; 133: 331-339.

22 Al ST, Cottrell DA, Hughes CV: Dental findings associated with the malformations of CHARGE. Pediatr Dent 2002; 24: 43-46.

23 Ozeki H, Shirai S, Nozaki M, Ikeda K, Ogura Y: Maldevelopment of neural crest cells in patients with typical uveal coloboma. $J$ Pediat Ophthalmol Strabismus 1999; 36: 337-341.
24 Russell-Eggitt IM, Blake KD, Taylor DS, Wyse RK: The eye in the CHARGE association. Br J Ophthalmol 1990; 74: 421-426.

25 Wright CG, Brown OE, Meyerhoff WL, Rutledge JC: Auditory and temporal bone abnormalities in CHARGE association. Ann Otol Rhinol Laryngol 1986; 95: 480-486.

26 Morgan D, Bailey M, Phelps P, Bellmanj S, Grace A, Wyse R: Earnose-throat abnormalities in the CHARGE association. Arch Otol Head Neck Surg 1993; 119: 49-54.

27 Lemmerling M, Dhooge I, Mollet P, Mortier G, Van CP, Kunnen M: CT of the temporal bone in the CHARGE association. Neuroradiology 1998; 40: 462-465.

28 Sekhar HK, Sachs M: Mondini defect in association with multiple congenital anomalies. Laryngoscope 1976; 86: 117-125.

29 Guyot JP, Gacek RR, DiRaddo P: The temporal bone anomaly in CHARGE association. Arch Otolaryngol Head Neck Surg 1987; 113: $321-324$

30 Abadie V, Wiener-Vacher S, Morisseau-Durand MP et al: Vestibular anomalies in CHARGE syndrome: investigations on and consequences for postural development. Eur J Pediatr 2000; 159: $569-574$.

31 Amiel J, Attié-Bitach T, Marianowski R et al: Temporal bone anomaly proposed as a major criteria for diagnosis of CHARGE syndrome. Am I Med Genet 2001; 99: 124-127.

32 Verloes A: Updated diagnostic criteria for CHARGE syndrome: a proposal. Am J Med Genet A 2005; 133: 306-308.

33 Satar B, Mukherji SK, Telian SA: Congenital aplasia of semicircular canals. Otol Neurotol 2003; 24: 437-446.

34 Wiener-Vacher SR, Amanou L, Denise P, Narcy P, Manach Y: Vestibular function in children with the CHARGE association. Arch Otolaryngol Head Neck Surg 1999; 125: 342-347.

35 Thelin JW, Mitchell JA, Hefner MA, Davenport SL: CHARGE syndrome Part II. Hearing loss. Int J Pediatr Otorhinolaryngol 1986; 12: $145-163$.

36 Leclerc JE, Fearon B: Choanal atresia and associated anomalies. Int J Pediatr Otorhinolaryngol 1987; 13: 265-272.

37 Lin AE, Siebert JR, Graham Jr JM: Central nervous system malformations in the CHARGE association. Am J Med Genet 1990; 37: 304-310.

38 Pinto G, Abadie V, Mesnage R et al: CHARGE syndrome includes hypogonadotropic hypogonadism and abnormal olfactory bulb development. I Clin Endocrinol Metab 2005; 90: 5621-5626.

39 Sanlaville D, Genevieve D, Bernardin C et al: Failure to detect an 8p22-8p23.1 duplication in patients with Kabuki (NiikawaKuroki) syndrome. Eur J Hum Genet 2005; 13: 690-693.

40 Chalouhi C, Faulcon P, Le BC, Hertz-Pannier L, Bonfils P, Abadie V: Olfactory evaluation in children: application to the CHARGE syndrome. Pediatrics 2005; 116: e81-e88.

41 Byerly KA, Pauli RM: Cranial nerve abnormalities in CHARGE association. Am J Med Genet 1993; 45: 751-757.

42 White DR, Giambra BK, Hopkin RJ, Daines CL, Rutter MJ: Aspiration in children with CHARGE syndrome. Int $J$ Pediatr Otorhinolaryngol 2005; 69: 1205-1209.

43 Khadilkar VV, Cameron FJ, Stanhope R: Growth failure and pituitary function in CHARGE and VATER associations. Arch Dis Childhood 1999; 80: 167-170.

44 Wheeler PG, Quigley CA, Sadeghi-Nejad A, Weaver DD: Hypogonadism and CHARGE association. Am J Med Genet 2000; 94: 228-231.

45 Jongmans M, Admiraal R, van der DK: CHARGE syndrome: the phenotypic spectrum of mutations in the CHD7 gene. J Med Genet 2005, eprint.

46 Blake K, Kirk JM, Ur E: Growth in CHARGE association. Arch Dis Childhood 1993; 68: 508-509.

47 Dobbelsteyn C, Marche DM, Blake K, Rashid M: Early oral sensory experiences and feeding development in children with CHARGE syndrome: a report of five cases. Dysphagia 2005; 20 : $89-100$.

48 Ragan DC, Casale AJ, Rink RC, Cain MP, Weaver DD: Genitourinary anomalies in the CHARGE association. J Urol 1999; 161: $622-625$ 
49 Blake KD, Salem-Hartshorne N, Daoud MA, Gradstein J: Adolescent and adult issues in CHARGE syndrome. Clin Pediatr (Philadelphia) 2005; 44: 151-159.

50 Wyse RK, al-Mahdawi S, Burn J, Blake K: Congenital heart disease in CHARGE association. Pediatr Cardiol 1993; 14: 75-81.

51 Allouche C, Sarda P, Tronc F, Jalaguier J, Montoya F, Bonnet H: [The CHARGE association]. Pediatrie 1989; 44: 391-395.

52 Theodoropoulos DS: Immune deficiency in CHARGE association. Clin Med Res 2003; 1: 43-48.

53 De Lonlay-Debeney P, Cormier-Daire V, Amiel J et al: Features of DiGeorge syndrome and CHARGE association in five patients. J Med Genet 1997; 34: 986-989.

54 Brock KE, Mathiason MA, Rooney BL, Williams MS: Quantitative analysis of limb anomalies in CHARGE syndrome: correlation with diagnosis and characteristic CHARGE anomalies. Am J Med Genet $A$ 2003; 123: 111-121.

55 Doyle C, Blake K: Scoliosis in CHARGE: a prospective survey and two case reports. Am J Med Genet A 2005; 133: 340-343.

56 Money J, Norman BF: Pedagogical handicap associated with micropenis and other CHARGE syndrome anomalies of embryogenesis: four 46, XY cases reared as girls. Am J Psychother 1988; 42: $354-379$.

57 Raqbi F, Le BC, Morisseau-Durand MP, Dureau P, Lyonnet S, Abadie V: Early prognostic factors for intellectual outcome in CHARGE syndrome. Dev Med Child Neurol 2003; 45: 483-488.

58 Graham Jr JM, Rosner B, Dykens E, Visootsak J: Behavioral features of CHARGE syndrome (Hall-Hittner syndrome) comparison with Down syndrome, Prader-Willi syndrome, and Williams syndrome. Am J Med Genet A 2005; 133: 240-247.

59 Smith IM, Nichols SL, Issekutz K, Blake K: Behavioral profiles and symptoms of autism in CHARGE syndrome: preliminary Canadian epidemiological data. Am J Med Genet A 2005; 133: 248-256.

60 Salem-Hartshorne N, Jacob S: Adaptive behavior in children with CHARGE syndrome. Am J Med Genet A 2005; 133: 262-267.

61 Lalani SR, Safiullah AM, Fernbach SD et al: Spectrum of CHD7 Mutations in 110 Individuals with CHARGE Syndrome and Genotype-Phenotype Correlation. Am J Hum Genet 2006; 78: 303-314.

62 Aramaki M, Udaka T, Kosaki R et al: Phenotypic spectrum of CHARGE syndrome with CHD7 mutations. J Pediatr 2006; 148: 410-414.

63 Mitchell JA, Davenport SL, Hefner MA, Shei MM: Use of an expert model to test diagnostic criteria in CHARGE syndrome. J Med Syst 1985; 9: 425-436.

64 Hertzberg BS, Kliewer MA, Lile RL: Antenatal ultrasonographic findings in the CHARGE association. J Ultrasound Med 1994; 13: $238-242$.

65 Becker R, Stiemer B, Neumann L, Entezami M: Mild ventriculomegaly, mild cerebellar hypoplasia and dysplastic choroid plexus as early prenatal signs of CHARGE association. Fetal Diagn Ther 2001; 16: 280-283.

66 Jongmans M, Sistermans EA, Rikken A et al: Genotypic and phenotypic characterization of Noonan syndrome: new data and review of the literature. Am J Med Genet A 2005; 134: $165-170$.

67 Nagase T, Kikuno R, Ishikawa KI, Hirosawa M, Ohara O: Prediction of the coding sequences of unidentified human genes. XVI. The complete sequences of 150 new cDNA clones from brain which code for large proteins in vitro. DNA Res 2000; 7: $65-73$

68 Vissers LE, van Ravenswaaij CM, Admiraal R et al: Mutations in a new member of the chromodomain gene family cause CHARGE syndrome. Nat Genet 2004; 36: 955-957.

69 Hurst JA, Meinecke P, Baraitser M: Balanced t(6;8)(6p8p;6q8q) and the CHARGE association. J Med Genet 1991; 28: 54-55.

70 Arrington CB, Cowley BC, Nightingale DR, Zhou H, Brothman $\mathrm{AR}$, Viskochil DH: Interstitial deletion 8q11.2-q13 with congenital anomalies of CHARGE association. Am J Med Genet A 2005; 133: 326-330.
71 Johnson DS, Morrison N, Grant L et al: Confirmation of CHD7 as a cause of CHARGE association identified by mapping a balanced chromosome translocation in affected monozygotic twins. J Med Genet 2006; 43: 280-284.

72 Woodage T, Basrai MA, Baxevanis AD, Hieter P, Collins FS: Characterization of the CHD family of proteins. Proc Natl Acad Sci USA 1997; 94: 11472-11477.

73 Brehm A, Tufteland KR, Aasland R, Becker PB: The many colours of chromodomains. Bioessays 2004; 26: 133-140.

74 Dirscherl SS, Krebs JE: Functional diversity of ISWI complexes. Biochem Cell Biol 2004; 82: 482-489.

75 Schachen PC, Tie F, Lalani SR, Belmont JW, Collins FS: The CHD7 protein, mutated in CHARGE syndrome, binds to specific sites on chromatin (A19). Am J Med Genet 2006; 79 (suppl. 1): 20.

76 Kosaki K, Udaka T, Okuyama T: DHPLC in clinical molecular diagnostic services. Mol Genet Metab 2005; 86: 117-123.

77 Bosman EA, Penn AC, Ambrose JC, Kettleborough R, Stemple DL, Steel KP: Multiple mutations in mouse Chd7 provide models for CHARGE syndrome. Hum Mol Genet 2005; 14: 3463-3476.

78 Sanlaville D, Etchevers HC, Gonzales $\mathrm{M}$ et al: Phenotypic spectrum of CHARGE syndrome in fetuses with CHD7 truncating mutations correlates with expression during human development. J Med Genet 2005.

79 Lalani SR, Safiullah AM, Molinari LM, Fernbach SD, Martin DM, Belmont JW: SEMA3E mutation in a patient with CHARGE syndrome. J Med Genet 2004; 41: e94.

80 Devriendt K, Swillen A, Fryns JP: Deletion in chromosome region 22q11 in a child with CHARGE association. Clin Genet 1998; 53: 408-410.

81 Smithells RW: Defects and disabilities of thalidomide children. BMJ 1973; 1: 269-272.

82 James WH: Clomiphene, anencephaly, and spina bifida. Lancet $1977 ; 1: 603$.

83 Grix Jr A: Malformations in infants of diabetic mothers. Am J Med Genet 1982; 13: 131-137.

84 Sulik KK, Johnston MC, Daft PA, Russell WE, Dehart DB: Fetal alcohol syndrome and DiGeorge anomaly: critical ethanol exposure periods for craniofacial malformations as illustrated in an animal model. Am J Med Genet Suppl 1986; 2: 97-112.

85 Stromland K, Miller MT: Thalidomide embryopathy: revisited 27 years later. Acta Ophthalmol (Copenhagen) 1993; 71: 238-245.

86 Siebert JR, Graham JMJ, McDonald C: Pathologic features of the CHARGE association: support for involvement of the neural crest. Teratology 1985; 31: 331-336.

87 Kirby ML, Waldo KL: Role of neural crest in congenital heart disease. Circulation 1990; 82: 332-340.

88 Van Meter TD, Weaver DD: Oculo-auriculo-vertebral spectrum and the CHARGE association: clinical evidence for a common pathogenetic mechanism. Clin Dysmorphol 1996; 5: 187-196.

89 Kallen K, Robert E, Castilla EE, Mastroiacovo P, Kallen B: Relation between oculo-auriculo-vertebral (OAV) dysplasia and three other non-random associations of malformations (VATER, CHARGE, and OEIS). Am J Med Genet A 2004; 127: 26-34.

90 Lemmerling MM, Vanzieleghem BD, Mortier GR, Dhooge IJ, Kunnen MF: Unilateral semicircular canal aplasia in Goldenhar's syndrome. AJNR Am J Neuroradiol 2000; 21: 1334-1336.

91 Hill J, Elliott C, Colquhoun I: Audiological, vestibular and radiological abnormalities in Kallman's syndrome. J Laryngol Otol 1992; 106: 530-534.

92 Clementi M, Tenconi R, Turolla L, Silvan C, Bortotto L, Artifoni L: Apparent CHARGE association and chromosome anomaly: chance or contiguous gene syndrome. Am J Med Genet 1991; 41: 246-250.

93 Wieczorek D, Bolt J, Schwechheimer K, Gillessen-Kaesbach G: A patient with interstitial deletion of the short arm of chromosome 3 (pter->p21.2::p12-> qter) and a CHARGE-like phenotype. Am J Med Genet 1997; 69: 413-417.

94 North KN, Wu BL, Cao BN, Whiteman DA, Korf BR: CHARGE association in a child with de novo inverted duplication (14)(q22-> q24.3). Am J Med Genet 1995; 57: 610-614. 
95 Lee WT, Hou JW, Yau KI, Wang TR: Trisomy 18 in a patient with CHARGE association. J Formos Med Assoc 1995; 94: 60-62.

96 De Krijger RR, Mooy CM, Van Hemel JO et al: CHARGE association-related ocular pathology in a newborn with partial trisomy $19 \mathrm{q}$ and partial monosomy $21 \mathrm{q}$, from a maternal translocation (19;21) (q13.1;q22.3). Pediatr Dev Pathol 1999; 2: 577-581.

97 Lev D, Nakar O, Bar-Am I et al: CHARGE association in a child with de Novo chromosomal aberration 46, X,der(X)t(X;2)(p22.1; 433$)$ detected by spectral karyotyping. J Med Genet 2000; 37: E47.
98 Dev VG, Bulter MG, Phillips JA: 1q duplication due to unequal crossover in a patient with CHARGE association and DiGeorge squence. Am J Hum Genet 1985; 37: A90 (264).

99 Abeliovich D, Yagupsky P: Bashan N. 3:1 meiotic disjunction in a mother with a balanced translocation, $46, \mathrm{XX}, \mathrm{t}(5,14)(\mathrm{p} 15 ; \mathrm{q} 13)$ resulting in tertiary trisomy and tertiary monosomy offspring. Am J Med Genet 1982; 12: 83-89.

100 Townes PL, White MR: Inherited partial trisomy 8q (22 leads to qter). Am J Dis Children 1978; 132: 498-501. 